\title{
Variation in Sexual Orientation Documentation in a National Electronic Health Record System
}

\author{
Kristine E. Lynch, PhD, ${ }^{1,2}$ Benjamin Viernes, MPH, ${ }^{1,2}$ Karen C. Schliep, PhD, ${ }^{3}$ Elise Gatsby, MPH, \\ Patrick R. Alba, MS, ${ }^{1,2}$ Scott L. DuVall, PhD, ${ }^{1,2}$ and John R. Blosnich, PhD, MPH ${ }^{4,5}$
}

\begin{abstract}
Purpose: The purpose of this study was to determine variation in sexual minority (SM) sexual orientation documentation within the electronic medical records of the Veterans Health Administration (VHA).

Methods: Documentation of SM sexual orientation was retrospectively extracted from clinical notes and administrative data in the VHA from October 1, 1999 to July 1, 2019. The rate of documentation overall and by calendar year was calculated, and differences across patient, provider, and clinic characteristics were evaluated.

Results: Approximately $1.4 \%$ of all VHA Veterans $(n=115,911)$ had at least one documentation of SM sexual orientation, including 79,455 men and 36,456 women. The rate of documentation increased from 81.01/100,000 in 2000 to $568.84 / 100,000$ in 2018. The majority of documentations (58.7\%) occurred in mental health settings by non-MD mental health/social work counselors, whereas only $9.6 \%$ occurred in primary care settings. Although $99 \%$ of these Veterans had a primary care visit, only 19\% had SM status recorded in that setting.

Conclusion: Documentation patterns of SM sexual orientation varied considerably in the VHA with notable gaps in primary care. Diverse approaches to culturally competent training for primary care clinicians and patientfacing collection strategies could facilitate documentation of sexual orientation.
\end{abstract}

Keywords: administrative data or large data sets, natural language processing, sexual orientation, Veterans/ Department of Veterans Affairs/VA

\section{Introduction}

$\mathbf{S}$ EXUAL MINORITY (SM) individuals face challenges and stressors because of their sexual orientation identity. ${ }^{1,2}$ The minority stress framework proposes that exposure to chronic and acute levels of stress due to stigmatization, discrimination, and concealment of sexual orientation can contribute to both mental ${ }^{3}$ and physical health ${ }^{4,5}$ consequences, many of which can be ameliorated with timely health services. Open dialogue surrounding sexual orientation is essential for providing patient-centered health care through providers effectively responding to health inequities potentially associated with patients' sexual orientation and sexual behaviors.

Patients who communicate their sexual orientation to providers also reap several health benefits following disclosure, including decreased minority stress, as well as more effective service utilization and higher satisfaction with providers. ${ }^{6}$
For instance, providers can more appropriately recommend health testing for sexually transmitted infections (STIs) ${ }^{7}$ and emphasize the importance of screenings, such as Pap testing among lesbian and bisexual women. ${ }^{8}$ In addition to sexual health benefits, one study found that lesbian women who disclosed their sexual orientation to a provider were more likely to have seen a physician in the previous 6 months and to have higher self-perception of their health status than those who did not disclose their sexual orientation. ${ }^{9}$

The decision to communicate sexual orientation to a provider is multifaceted. ${ }^{10,11}$ It can be shaped by the level of patient-provider trust, as well as patient traits such as age, ${ }^{12,13}$ education, parity, and internalized homonegativity. ${ }^{14}$ Provider characteristics can also influence disclosure. For example, one study found that the age, sex, and sexual orientation of the provider were associated with knowledge of patients' sexual orientation, with younger, female, and SM providers being more aware of patients' sexual orientation. ${ }^{15}$

\footnotetext{
${ }^{1}$ VA Informatics and Computing Infrastructure, VA Salt Lake City Health Care System, Salt Lake City, Utah, USA.

${ }^{2}$ Division of Epidemiology, Department of Internal Medicine, University of Utah, Salt Lake City, Utah, USA.

${ }^{3}$ Department of Family and Preventive Medicine, University of Utah, Salt Lake City, Utah, USA.

${ }^{4}$ Suzanne Dworak-Peck School of Social Work, University of Southern California, Los Angeles, California, USA.

${ }^{5}$ Center for Health Equity Research and Promotion, VA Pittsburgh Healthcare System, Pittsburgh, Pennsylvania, USA.
} 
Other providers only broach the topic of sexual orientation when they think the information is directly relevant to the health care being provided. ${ }^{16}$

The Veterans Health Administration (VHA), as the largest integrated health care system in the United States, is likely the largest single health care provider for SM individuals. However, previous qualitative research suggests that VHA providers do not consistently assess patients' sexual orientation in clinical practice, ${ }^{17-19}$ despite extant literature strongly suggesting its utility for comprehensive patient-centered care and the willingness of Veterans to disclose sexual orientation if asked. ${ }^{20,21}$ The leading reasons for VHA providers not talking with patients about sexual orientation are similar to reasons reported by non-VHA providers, ${ }^{22,23}$ including fear of offending patients, not considering the information pertinent to health care, and believing that patients would bring up sexual orientation if they felt that it was important. ${ }^{18}$ Disclosure apprehension among SM Veterans is rooted in fear of mistreatment and stigmatization ${ }^{24,25}$ and the belief that patients should initiate discussions about sexual orientation. ${ }^{17,24}$

Existing research on the assessment and disclosure of sexual orientation in the VHA provides useful data about the inadequacy of its occurrence, but it is limited by the crosssectional nature of the studies and the reliance on selfreported data from convenience samples in geographically limited areas. ${ }^{17-19,24,25}$ A comprehensive nationwide characterization of documentation patterns can identify clinical specialties or patient subpopulations in which documentation practices can improve. Despite recommendations by the National Academy of Medicine for electronic health records (EHRs) to include sexual orientation ${ }^{26}$ and VHA directives to consistently collect sexual orientation data in the $\mathrm{VHA}^{27}$ it is not yet systematically implemented as a structured field in the medical record. However, our previous work revealed that sexual orientation is often documented in nonstandardized clinical notes and can be extracted using natural language processing (NLP). ${ }^{28}$ The aims of this study were to quantify the existence and describe patterns of documentation of SM sexual orientation within VHA's nationwide EHR.

\section{Methods}

\section{Data source}

We used clinical notes and administrative data from the VHA Corporate Data Warehouse (CDW) to identify and characterize documentation of SM sexual orientation from October 1, 1999 to July 1, 2019 (beginning of the VHA EHR - date of data acquisition and study execution) for all Veterans who enrolled in the VHA after FY2000. The University of Utah Institutional Review Board approved this study. As the study was retrospective and posed no more than minimal risk to participants the requirement for informed consent was waived.

\section{SM status documentation}

SM status documentation was considered as any record of administrative coding for "homosexual" or "bisexual" sexual orientation (Table 1) or statements in the clinical notes that were both in relation to the patient and a confirmation
Table 1. Administrative Codes FOR SEXUAL ORIENTATION

\begin{tabular}{ll}
\hline $\begin{array}{l}\text { ICD } \\
\text { code }\end{array}$ & \multicolumn{1}{c}{$\begin{array}{c}\text { Code } \\
\text { description }\end{array}$} \\
\hline ICD-9 Code 302.0 & $\begin{array}{l}\text { Ego-dystonic homosexuality } \\
\text { Trans-sexualism with homosexual } \\
\text { history }\end{array}$ \\
ICD-10 Code Z72.52 & $\begin{array}{l}\text { High risk homosexual behavior } \\
\text { High risk bisexual behavior }\end{array}$ \\
\hline
\end{tabular}

The code list is not an exhaustive list but rather representative of codes that existed in the VHA electronic health record.

ICD, International Classification of Diseases; VHA, Veterans Health Administration.

of the patient's sexual orientation as anything other than heterosexual orientation or being in an other-sex partnership. Clinical notes were evaluated using NLP, which is described in detail elsewhere. ${ }^{28}$ Briefly, a series of concept dictionaries identified all known terms used to describe lesbian, gay, or bisexual orientation. A combination of rule-based NLP and machine learning identified and categorized instances of terms related to patient sexual orientation. The NLP output contained instance level categorization of SM documentation. The first documentation of SM sexual orientation, either by code or note, was considered index documentation.

\section{Patient-level evaluation}

Veterans with $\geq 1$ instance of SM documentation were assigned to a mutually exclusive sexual orientation category using structured data on birth sex within the CDW (hereinafter referred to as SM male or SM female). Patients were further described according to time-fixed demographic characteristics, including age at first VHA visit, race, ethnicity, history of Military Sexual Trauma (MST), and service connection percentage (the degree to which a Veteran is disabled due to injury/illness caused or made worse by military service). Health care utilization was defined by the number of health care encounters within the VHA grouped by visit type and clinical setting. Time from first VHA encounter to index documentation in calendar time (days) and clinical time (visits) was assessed.

\section{Documentation and provider-level evaluation}

Each documentation was linked to the visit location of the encounter corresponding to the clinical note or the administrative record. VHA stop codes identified the visit location and were categorized into the following: inpatient, primary care, mental health, social work, women's health, infectious disease, emergency/urgent care, other clinical specialty, and unknown. In addition, documentation was linked to the author of the clinical note or provider of record of the administrative data to determine the frequency of documentation by provider credential. Provider degree and position title were manually curated into the following categories: attending and resident physician, non-MD mental health/social work counselor, physician assistant or advanced practice nurse, nursing service (e.g., registered nurse), pharmacist/tech, nonmental health therapist (e.g., physical therapist), and nonphysician clinical specialist (e.g., dietitian). 


\section{Statistical analyses}

Descriptive statistics at the patient level were used to compare characteristics of the SM cohort to Veterans without SM sexual orientation documentation (hereinafter referred to as non-SM Veterans) by sex and were contrasted using Chisquare tests for categorical variables and $t$-tests for continuous variables. Trends in documentation using crude rates of documentation by fiscal year (per 100,000 persons) and by sex are presented.

\section{Results}

Of the 8.4 million Veterans who enrolled in the VHA after FY2000, 115,911 ( 1.4\%) Veterans had at least one documentation of SM sexual orientation, with $31.5 \%$ being SM female compared with only $6 \%$ of the non-SM population being female. Individuals in the SM cohort were more likely to be younger at first VHA encounter and to have some level of military service connection compared with non-SM Veterans. Both SM males and females were significantly more likely to have a record of history of MST compared with their non-SM counterparts (10\% vs. $1 \%$ and $43 \%$ vs. $21 \%$, respectively, $p<0.001$ ) (Table 2 ).

The total number of SM documentations was 449,957 (mean: 3.8 documentations/patient). The majority (97\%) of the 115,911 SM Veterans had documentation of sexual orientation only within clinical notes, but $603(<1 \%)$ had only an administrative code and 2379 (2\%) had records of both types. The most common administrative code was International Classification of Diseases (ICD)-10 code "Z72.52," High Risk Homosexual Behavior $(71.6 \%$ of all code instances), occurring mostly for gay men (96\% of all code instances) in infectious disease clinics (41.1\%) between 2016 and July 2019 (88\%).

The average age at index documentation was 48 years with the average age for SM males being 51 years and SM females being 40 years. The average number of days and visits to index documentation was 1878 and 137, respectively. SM females tended to have documentation 137 days sooner than men, on average (1783 vs. 1920 days since first VHA

Table 2. Characteristics of Sexual Minority Veterans Compared to the Non Sexual Minority Veteran Population by BirTh SeX

\begin{tabular}{|c|c|c|c|c|c|c|}
\hline \multirow[b]{2}{*}{ Characteristic } & \multicolumn{3}{|c|}{ Male birth sex } & \multicolumn{3}{|c|}{ Female birth sex } \\
\hline & $\begin{array}{c}\text { Non-SM Veteran } \\
\text { population } \\
(\mathrm{N}=7,760,804) \\
\mathrm{n}(\%)\end{array}$ & $\begin{array}{c}\text { SM Veteran } \\
\text { population } \\
(\mathrm{N}=79,455) \\
\mathrm{n}(\%)\end{array}$ & $\mathrm{p}$ & $\begin{array}{c}\text { Non-SM Veteran } \\
\text { population } \\
(\mathrm{N}=550,623) \\
\mathrm{n}(\%)\end{array}$ & $\begin{array}{c}\text { SM Veteran } \\
\text { population } \\
(\mathrm{N}=36,456) \\
\mathrm{n}(\%)\end{array}$ & $\mathrm{p}$ \\
\hline Race & & & $<0.001$ & & & $<0.001$ \\
\hline White & $5,207,107(67)$ & $57,811(73)$ & & $301,228(54)$ & $22,759(63)$ & \\
\hline Black or African American & $844,098(11)$ & $13,921(18)$ & & $136,802(25)$ & $9,662(27)$ & \\
\hline Other/unknown & $1,709,599(22)$ & $7723(9)$ & & $112,593(21)$ & $4035(11)$ & \\
\hline Ethnicity & & & $<0.001$ & & & $<0.001$ \\
\hline Hispanic or Latino & $381,359(5)$ & $6874(9)$ & & $38,827(7)$ & $3818(10)$ & \\
\hline Age at first VHA visit & & & $<0.001$ & & & $<0.001$ \\
\hline Mean and (standard deviation) & $56.45(17.8)$ & $45.53(15.9)$ & & $40.5(16.1)$ & $35.02(12.2)$ & \\
\hline Age group at first VHA visit, years & & & $<0.001$ & & & $<0.001$ \\
\hline $18-29$ & $899,060(12)$ & $17,765(22)$ & & $183,817(33)$ & $16,203(44)$ & \\
\hline $30-39$ & $614,566(8)$ & $11,782(15)$ & & $109,680(20)$ & $7788(21)$ & \\
\hline $40-49$ & $907,759(12)$ & $15,901(20)$ & & $113,061(20)$ & $7130(20)$ & \\
\hline $50-59$ & $1,441,223$ (19) & $17,905(23)$ & & $70,256(13)$ & $4036(11)$ & \\
\hline $60-69$ & $1,800,615(23)$ & $10,657(13)$ & & $28,143(5)$ & $920(3)$ & \\
\hline $70-79$ & $1,310,376(17)$ & $3994(5)$ & & $17,801(3)$ & $208(<1)$ & \\
\hline $80+$ & $638,716(8)$ & $1407(2)$ & & $16,972(3)$ & $107(<1)$ & \\
\hline Unknown & $148,489(2)$ & $44(<1)$ & & $10,893(2)$ & $64(<1)$ & \\
\hline Service connection & & & $<0.001$ & & & $<0.001$ \\
\hline Yes & $3,597,807$ (46) & $46,677(59)$ & & $343,675(61)$ & $28,015(77)$ & \\
\hline Service connection & & & $<0.001$ & & & $<0.001$ \\
\hline $0-49$ & $1,666,645(21)$ & $12,964(16)$ & & $128,297(23)$ & $5841(16)$ & \\
\hline $50+$ & $1,931,162(25)$ & $33,713(42)$ & & $215,378(38)$ & $22,174(61)$ & \\
\hline No service connection & $4,156,282(53)$ & $32,760(41)$ & & $205,295(37)$ & $8415(23)$ & \\
\hline Unknown & $6715(<1)$ & $18(<1)$ & & $1653(<1)$ & $26(<1)$ & \\
\hline Military sexual trauma & & & $<0.001$ & & & $<0.001$ \\
\hline Yes & 80,155 (1) & $8076(10)$ & & $115,299(21)$ & $15,542(43)$ & \\
\hline No & $6,424,293(83)$ & $69,665(88)$ & & $348,481(62)$ & $20,532(56)$ & \\
\hline Decline to answer & $14,239(<1)$ & $104(<1)$ & & $1373(<1)$ & $33(<1)$ & \\
\hline Unknown & $1,242,117(16)$ & $1610(2)$ & & $85,470(15)$ & $349(<1)$ & \\
\hline
\end{tabular}

SM Veterans: includes only those sexual minority Veterans with documentation of sexual minority sexual orientation in the VHA electronic medical record. Non-SM Veterans: includes only those Veterans without documentation of sexual minority sexual orientation. SM, sexual minority. 
encounter, $p<0.01)$. Index documentation for $24.4 \%$ of SM Veterans occurred within the 1st year of enrollment with no statistically significant difference observed between SM males and females $(p=0.52)$.

A total of 82,230 distinct providers $(5.8 \%$ of all providers who have ever signed a clinical note) documented SM sexual orientation throughout the $\sim 20$-year period. More than half of the providers documented for only 1 SM patient, but 3463 $(4.2 \%)$ documented for $>10$ SM patients. Physicians made up the largest category of providers who documented SM sexual orientation (20.7\%), but non-MD mental health/social work counselors, who represented $14.0 \%$ of all providers who documented, were responsible for the largest percentage of documented instances $(40.1 \%$ compared with $37.0 \%$ by phy- sicians). Corresponding to the share of documentation provided by mental health staff, $58.7 \%$ of all documentation occurred within a mental health clinical setting. The second most common setting for SM documentation, primary care, contributed to only $9.6 \%$ of instances. The "other clinical specialty" category included 87 stop codes (e.g., endocrinology, urology) and collectively accounted for $3.9 \%$ of all documentations. Figure 1 displays SM documentation by clinic setting and patient sex.

Figure 2 indicates the increasing trend of index documentation rates by SM category. Documentation occurred throughout time, but the majority (76\%) occurred after the repeal of Don't Ask Don't Tell (DADT) on September 20, 2011, a policy barring gay men and women from serving

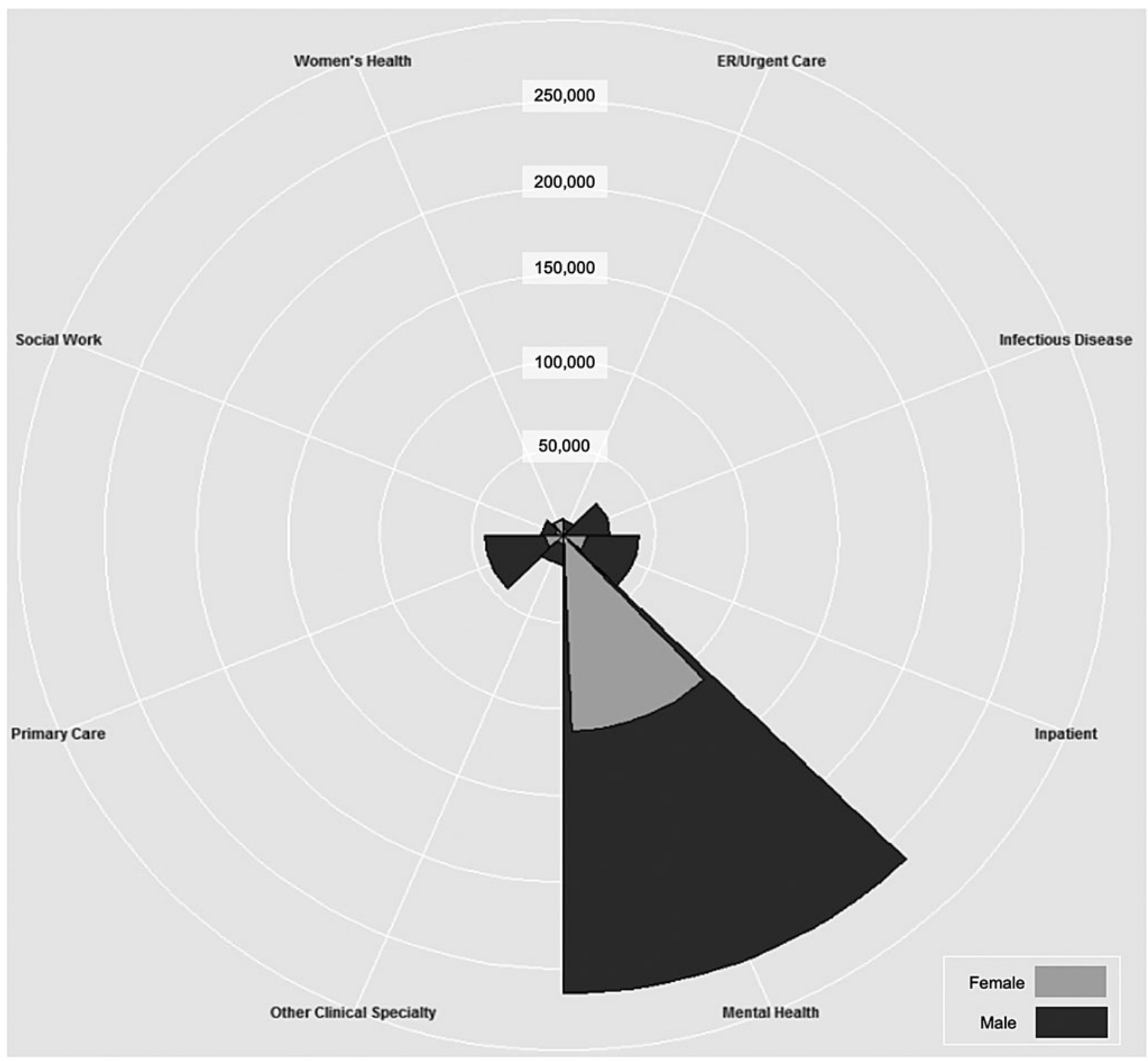

FIG. 1. Diagram of the clinic setting of sexual minority documentation by patient sex. Each clinical setting is represented by a separate slice of the figure. The area of each slice represents the number of documentations in the corresponding clinical setting. The change in color (gray to black or black to gray) represents the higher number of documentations for sexual minority males or females, respectively. ER, emergency room. 

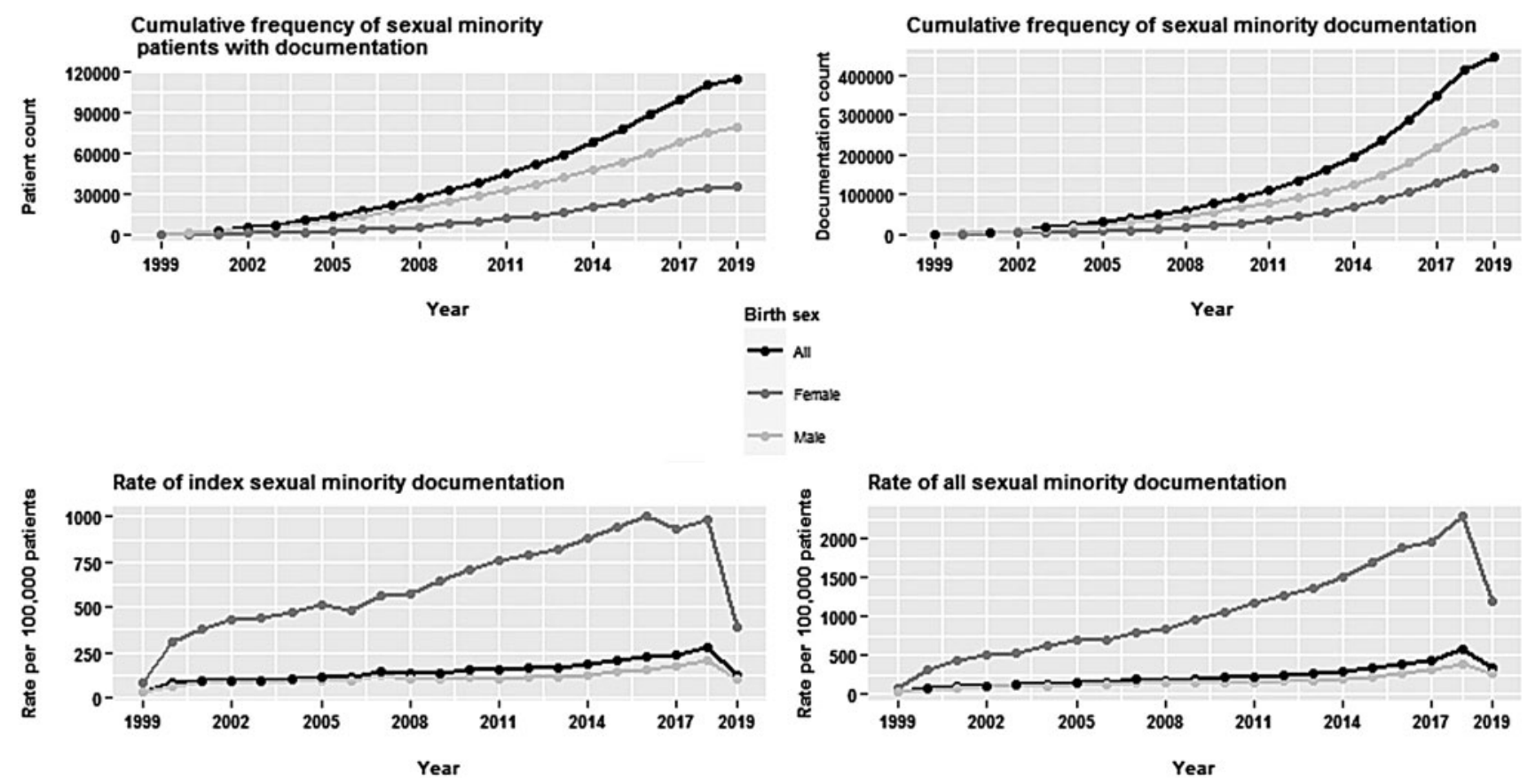

FIG. 2. Documentation of sexual minority sexual orientation across time in the Veterans Health Administration, October 1, 1999 to July 1, 2019. Complete data for years 1999 and 2019 were not available. Therefore, rates and counts may not be reflective of the entire calendar year for those 2 years.

openly in the military. ${ }^{29}$ The highest index documentation rate was in 2018 (275.4 per 100,000 active users). The highest rate for SM females was in 2016 (1006.7 per 100,000 active users) and for males was 2018 (206.4 per 100,000 active users). Rates of all SM documentation had similar trends. Overall rates increased from $81.01 / 100,000$ in 2000 to 568.84/100,000 in 2018 (Fig. 2).

SM Veterans utilized VHA across a variety of clinical settings across the 20-year period (99\% having at least one primary care visit, $90 \%$ mental health, $76 \%$ emergency/urgent care, and 19\% infectious disease); however, documentation of SM status in those settings was inconsistent. The percentage of Veterans with at least one SM documentation in these four settings was $19 \%, 70 \%, 6 \%$, and $33 \%$, respectively (Table 3 ).

\section{Discussion}

Using data from the VHA EHR, this is the first patient-level evaluation of variation in SM sexual orientation documentation. The rate of documentation varied significantly across time and by patient, provider, and clinic characteristics. Unsurprisingly, the rate of documentation increased over time.

Table 3. Utilization of Veterans Health Administration Health Care Services and Sexual Minority Sexual Orientation Documentation by Clinic Setting

\begin{tabular}{|c|c|c|c|c|}
\hline Clinical setting & $\begin{array}{c}\text { Female }(\mathrm{N}=36,456) \\
\mathrm{n}(\%)\end{array}$ & $\begin{array}{c}\text { Male }(\mathrm{N}=79,455) \\
\mathrm{n}(\%)\end{array}$ & $\begin{array}{c}\text { Total }(\mathrm{N}=115,911) \\
\mathrm{n}(\%)\end{array}$ & $\mathrm{p}$ \\
\hline \multicolumn{5}{|l|}{ Primary care } \\
\hline Visit & $35,765(98.1)$ & $78,633(99.0)$ & $114,398(98.7)$ & $<0.001$ \\
\hline Documentation & $5974(16.7)$ & 15,633 (19.9) & 21,607 (18.9) & $<0.001$ \\
\hline \multicolumn{5}{|l|}{ ER/urgent care } \\
\hline Visit & $28,229(77.4)$ & $59,610(75.0)$ & $87,839(75.8)$ & $<0.001$ \\
\hline Documentation & $1922(6.8)$ & $3434(5.8)$ & $5356(6.1)$ & $<0.001$ \\
\hline \multicolumn{5}{|c|}{ Infectious disease care } \\
\hline Visit & $3041(8.3)$ & $19,104(24.0)$ & $22,145(19.1)$ & $<0.001$ \\
\hline Documentation & $137(4.5)$ & $7072(37.0)$ & 7209 (32.6) & $<0.001$ \\
\hline \multicolumn{5}{|l|}{ Mental health } \\
\hline Visit & $34,551(94.8)$ & $70,274(88.4)$ & $104,825(90.4)$ & $<0.001$ \\
\hline Documentation & $26,201(75.8)$ & $47,269(67.3)$ & $73,470(70.1)$ & $<0.001$ \\
\hline \multicolumn{5}{|c|}{ All other clinic settings } \\
\hline Visit & $36,381(99.8)$ & 79,319 (99.8) & $115,700(99.8)$ & 0.200 \\
\hline Documentation & $11,501(31.6)$ & $19,525(24.6)$ & $31,026(26.8)$ & $<0.001$ \\
\hline
\end{tabular}

Documentation \% refers to the proportion of patients with documentation who had a visit in the same clinic setting. ER, emergency room. 
Amidst increasing social acceptance of SM individuals, LGBT-related policy both inside and outside of the military, ${ }^{27,30}$ and more positive perceptions of the VHA environment, ${ }^{31,32}$ SM Veterans may be more willing to use VHA health care and disclose their sexual orientation to providers than in earlier years.

We observed the majority of documentation after the repeal of DADT, which corroborates prior findings that SM Veterans reported less need for confidentiality and more willingness to disclose sexual orientation to VHA providers. ${ }^{24} \mathrm{In}$ 2017, VHA issued its first directive about providing affirming care to Veterans with SM identities, ${ }^{27}$ and since 2016 every VHA facility is required to have a LGBT Veteran Care Coordinator on staff ${ }^{33}$ who provides education and clinical consultation to VHA providers regarding LGBT policies and directives. Similarly, efforts are underway to improve medical curricula surrounding sexual orientation and gender identity (SOGI), ${ }^{34}$ and newer clinicians are being increasingly trained in understanding the health disparities experienced by sexual and gender minority (SGM) individuals. ${ }^{35,36}$ However, those further removed from their formative training years may have limited knowledge to communicate with and care for SM individuals.

These results suggest that SM Veterans and their providers are discussing sexual orientation, but disclosure may not be immediate upon entry into VHA. Although 25\% of SM Veterans had a documentation of SM status within the 1st year of receiving VHA services, the average time from first VHA visit to first SM documentation was 1878 days ( $\sim 61$ months). This trend was observed for both SM men and women. These results should be interpreted cautiously. Sexual orientation disclosure is not a bookended experience, but rather composed of multiple layers and milestones ${ }^{37}$ Furthermore, sexual identity, behavior, and attraction can evolve over time. Without information about where each Veteran was in their "coming out" process at the time of initial documentation, the significance of the observed delay is unclear. However, a non-VHA study found that the average time from first visit to first SGM documentation was 30 months, ${ }^{38}$ suggesting that disclosure in the VHA may be different than in non-VHA settings. More importantly, any delay in assessment and documentation of sexual orientation can have significant clinical implications. Among men who have sex with men, those who were unwilling to disclose their sexual orientation or sexual behaviors to providers avoided conversations altogether about sexual health, including STI testing and pre-exposure prophylaxis initiation. ${ }^{39}$ Another study reported that SM women had more positive health care experiences and were more willing to discuss sexual health issues with a provider who knew their sexual orientation. ${ }^{40}$

The majority of SM documentation occurred in mental health settings, whereas only $9.6 \%$ occurred in primary care settings. The primary care documentations favored SM males slightly, with only $16.7 \%$ of SM females having primary care documentation, compared with $19.9 \%$ of males, although $98.1 \%$ of the SM females had at least one primary care visit (i.e., theoretically had an opportunity for sexual orientation to be documented). The VHA Directive 1340 requires annual intake of sexual behavior for all Veterans regardless of sexual orientation. ${ }^{27}$ Although sexual orientation encompasses more than sexual behavior, the low frequency of documentation of SM sexual orientation in primary care settings suggests that sexual history assessments may not be occurring in the VHA as recommen- ded. Primary care is the most frequented clinical setting in the VHA and often the first point of entry into the health care system. Many of the health inequities faced by SM individuals (e.g., STIs, suicidal ideation, and MST) can be addressed in primary care settings, and gaps in documentation in primary care potentially suggest missed opportunities to deliver timely preventive services. For example, Sexton et al. reported higher rates of suicide attempts among SM Veterans who experienced MST compared with non-SM Veterans with MST. ${ }^{41}$ In our study, SM women were twice as likely to report MST than non-SM women Veterans (43\% vs. $21 \%$ ), which aligns with prior VHA survey research from 2013 (31\% vs. 13\%). ${ }^{42}$

The low occurrence of SM documentation in primary care settings is concerning but coincides with recent research outside the VHA. In 2016, the U.S. Bureau of Primary Health Care, Health Resources and Services Administration mandated routine collection of SOGI across its Health Center Program grantees, which are community-based primary care organizations in underserved communities. The authors evaluated the completeness of the 1st year of data collection across 1367 health centers and found that $77 \%$ of patients had missing sexual orientation data. ${ }^{43}$ Their results suggest that imposing a requirement to collect SOGI data alone is inadequate to impact provider behavior; it may need to be paired with educating both providers and patients about the importance and necessity of collecting this information. Additional work on barriers to and facilitators of disclosure and documentation can explore providers' beliefs and practices and elicit their preferences for training and education modalities, such as peer-led initiatives.

An example of such peers in health care may be social workers, which may be a particular strength in the VHA in terms of documentation of sexual orientation. A core tenet of social work practice is forming a rapport with individuals in their current situations (i.e., "meeting individuals where they are"). ${ }^{44}$ This rapport building could contribute to why social workers were among the most prevalent health care providers associated with SM documentation. Social workers are integrated in the VHA patient-aligned care team structuring akin to the patient-centered medical home model. ${ }^{45}$ Thus, social workers could be an internal resource for eliciting data from patients or helping to instruct fellow health care providers about facilitating conversations and clinical candor to set patients at ease with sharing this information.

\section{Limitations}

This study has limitations warranting further discussion. First, the results showed suboptimal documentation in VHA primary care settings, but that does not mean discussions about sexual orientation in primary care are not happening. The information extracted from the EHR serves only as a surrogate for the actual communication that occurred between a Veteran and provider. If information regarding sexual orientation was exchanged, the provider may not have considered it clinically relevant to the encounter and omitted the information from the EHR or the patient may have specifically requested that the information be withheld from their record. Therefore, results from this study may not be generalizable to all SM Veterans, but rather only to those who have disclosed their sexual orientation and had it documented in the medical record. 
Second, instances of SM sexual orientation were extracted using NLP. Although the system performed well, ${ }^{28}$ likely not all patients who disclosed SM status were correctly identified. However, the prevalence of SM Veterans found in the present study aligns with previous studies using alternative methodology. For example, among the 587,079 women Veterans evaluated in the present study, $6.2 \%$ were found to have SM documentation, whereas using Behavioral Risk Factor Surveillance Survey data, Blosnich et al. found that $5.9 \%$ of the women Veteran population self-identified as SM individuals. ${ }^{46}$ Although NLP can identify patients with indicators of SM status, we cannot infer from this information that the patient necessarily identifies as SM nor that individuals who have SM identity, attraction, or behavior do not have heterosexual identity, attraction, or behavior. Finally, using some structured data, although a form of documentation, can perpetuate stigma due to the use of antiquated language and some ICD codes within the biomedical field.

\section{Conclusion}

This is the largest study of SM Veterans to date, and it provides a valuable picture of current documentation practices in the VHA and points to areas for future improvement. Sexual orientation has not yet been introduced into the VHA EHR as a structured data field; however, the October 2020 U.S. Government Accountability Office report ${ }^{47}$ recommends consistent collection of SOGI data in the VHA EHR. In addition to provider education, concomitant largescale efforts are likely needed for patients to understand the importance and relevance of sexual orientation data in health care. Due to the legacy of DADT, Veterans may still have questions or concerns about being asked questions about sexual orientation. ${ }^{19}$ Future research is needed to determine optimum implementation strategies to improve documentation/disclosure in the VHA (e.g., patient facing web applications, provider incentives, audit, and feedback).

\section{Authors' Contributions}

K.E.L. contributed to the conception and design of the study, analysis and interpretation of data, and writing and critical revision of the article. B.V. contributed to data analysis and critical revision of the article. K.C.S. contributed to the interpretation of data and writing and critical revision of the article. E.G. contributed to data analysis and critical revision of the article. P.R.A. contributed to the design, development, and completion of the NLP system. S.L.D. contributed to the design and development of the NLP system. J.R.B. contributed to the interpretation of data and writing and critical revision of the article. All authors reviewed and approved the article before submission.

\section{Disclaimer}

The views expressed in this article are those of the authors and do not represent the views of the U.S. Department of Veterans Affairs.

\section{Author Disclosure Statement}

No competing financial interests exist.

\section{Funding Information}

This work was supported using resources and facilities at the VA Salt Lake City Health Care System and the VA Informatics and Computing Infrastructure (VINCI), VA HSR RES 13-457.

\section{References}

1. Mays VM, Cochran SD: Mental health correlates of perceived discrimination among lesbian, gay, and bisexual adults in the United States. Am J Public Health 2001;91: $1869-1876$.

2. Hatzenbuehler ML: How does sexual minority stigma "get under the skin"? A psychological mediation framework. Psychol Bull 2009;135:707-730.

3. Meyer IH: Prejudice, social stress, and mental health in lesbian, gay, and bisexual populations: Conceptual issues and research evidence. Psychol Bull 2003;129:674-697.

4. Lick DJ, Durso LE, Johnson KL: Minority stress and physical health among sexual minorities. Perspect Psychol Sci 2013;8:521-548.

5. Institute of Medicine (US) Committee on Lesbian, Gay, Bisexual, and Transgender Health Issues and Research Gaps and Opportunities. The Health of Lesbian, Gay, Bisexual, and Transgender People: Building a Foundation for Better Understanding. Washington, DC: National Academies Press, 2011.

6. Ruben MA, Fullerton M: Proportion of patients who disclose their sexual orientation to healthcare providers and its relationship to patient outcomes: A meta-analysis and review. Patient Educ Couns 2018;101:1549-1560.

7. Metheny N, Stephenson R: Disclosure of sexual orientation and uptake of HIV testing and hepatitis vaccination for rural men who have sex with men. Ann Fam Med 2016;14:155-158.

8. Curmi C, Peters K, Salamonson Y: Lesbians' attitudes and practices of cervical cancer screening: A qualitative study. BMC Womens Health 2014;14:153.

9. Mor Z, Eick U, Wagner Kolasko G, et al.: Health status, behavior, and care of lesbian and bisexual women in Israel. J Sex Med 2015;12:1249-1256.

10. Brooks H, Llewellyn CD, Nadarzynski T, et al.: Sexual orientation disclosure in health care: A systematic review. $\mathrm{Br} \mathrm{J}$ Gen Pract 2018;68:e187-e196.

11. Ogden SN, Scheffey KL, Blosnich JR, Dichter ME: "Do I feel safe revealing this information to you?": Patient perspectives on disclosing sexual orientation and gender identity in healthcare. J Am Coll Health 2020;68:617-623.

12. Nguyen GT, Yehia BR: Documentation of sexual partner gender is low in electronic health records: Observations, predictors, and recommendations to improve population health management in primary care. Popul Health Manag 2015;18:217-222.

13. Fenge LA, Hicks C: Hidden lives: The importance of recognising the needs and experiences of older lesbians and gay men within healthcare practice. Divers Health Care 2011;8:147-154.

14. Durso LE, Meyer IH: Patterns and predictors of disclosure of sexual orientation to healthcare providers among lesbians, gay men, and bisexuals. Sex Res Social Policy 2013;10:35-42.

15. Petroll AE, Mosack KE: Physician awareness of sexual orientation and preventive health recommendations to men who have sex with men. Sex Transm Dis 2011;38:63-67.

16. Kodadek LM, Peterson S, Shields RY, et al.: Collecting sexual orientation and gender identity information in the emergency department: The divide between patient and provider perspectives. Emerg Med J 2019;36:136-141. 
17. Sherman MD, Kauth MR, Shipherd JC, Street RL: Provider beliefs and practices about assessing sexual orientation in two Veterans Health Affairs hospitals. LGBT Health 2014;1:185-191.

18. Sherman MD, Kauth MR, Shipherd JC, Street RL: Communication between VA providers and sexual and gender minority veterans: A pilot study. Psychol Serv 2014;11:235-242.

19. Sherman MD, Kauth MR, Ridener L, et al.: An empirical investigation of challenges and recommendations for welcoming sexual and gender minority veterans into VA care. Prof Psychol Res Pr 2014;45:433-442.

20. Haider AH, Schneider EB, Kodadek LM, et al.: Emergency department query for patient-centered approaches to sexual orientation and gender identity: The EQUALITY Study. JAMA Intern Med 2017;177:819-828.

21. Ruben MA, Blosnich JR, Dichter ME, et al.: Will veterans answer sexual orientation and gender identity questions? Med Care 2017;55:S85-S89.

22. Goldhammer H, Maston ED, Kissock LA, et al.: National findings from an LGBT healthcare organizational needs assessment. LGBT Health 2018;5:461-468.

23. Maragh-Bass AC, Torain M, Adler R, et al.: Risks, benefits, and importance of collecting sexual orientation and gender identity data in healthcare settings: A multi-method analysis of patient and provider perspectives. LGBT Health 2017;4:141-152.

24. Mattocks KM, Sullivan JC, Bertrand C, et al.: Perceived stigma, discrimination, and disclosure of sexual orientation among a sample of lesbian veterans receiving care in the Department of Veterans Affairs. LGBT Health 2015;2:147-153.

25. Simpson TL, Balsam KF, Cochran BN, et al.: Veterans administration health care utilization among sexual minority veterans. Psychol Serv 2013;10:223-232.

26. Committee on the Recommended Social and Behavioral Domains and Measures for Electronic Health Records; Board on Population Health and Public Health Practice; Institute of Medicine. Capturing Social and Behavioral Domains and Measures in Electronic Health Records: Phase 2. Washington, DC: National Academies Press, 2015.

27. U.S. Department of Veterans Affairs: Provision of health care for Veterans who identify as lesbian, gay or bisexual. VHA Directive 1340(2), Transmittal Sheet, 2017 (amended 2020). Available at https://www.va.gov/vhapublications/ViewPub lication.asp?pub_ID=5438 Accessed November 17, 2020.

28. Lynch KE Alba PR, Patterson OV, et al.: The utility of clinical notes for sexual minority health research. Am J Prev Med 2020;59:755-763.

29. Katz KA: Health hazards of “'don't ask, don't tell.” N Engl J Med 2010;363:2380-2381.

30. Blosnich JR, Shipherd JC, Kauth MR: Are there differences in anti-gay beliefs among U.S. veterans and non-veterans? Results from the General Social Survey. J Homosex 2020: 67:1401-1411.

31. Kauth MR, Barrera TL, Latini DM: Lesbian, gay, and transgender veterans' experiences in the Veterans Health Administration: Positive signs and room for improvement. Psychol Serv 2019;16:346-351.

32. Shipherd JC, Darling JE, Klap RS, et al.: Experiences in the Veterans Health Administration and impact on healthcare utilization: Comparisons between LGBT and non-LGBT women veterans. LGBT Health 2018;5:303-311.

33. Valentine SE, Shipherd JC, Smith AM, Kauth MR: Improving affirming care for sexual and gender minority veterans. Psychol Serv 2019:10.1037/ser0000378.
34. Cooper MB, Chacko M, Christner J: Incorporating LGBT health in an undergraduate medical education curriculum through the construct of social determinants of health. MedEdPORTAL 2018;14:10781.

35. Sawning S, Steinbock S, Croley R, et al.: A first step in addressing medical education curriculum gaps in lesbian-, gay-, bisexual-, and transgender-related content: The University of Louisville Lesbian, Gay, Bisexual, and Transgender Health Certificate Program. Educ Health (Abingdon) 2017;30:108-114.

36. DeVita T, Bishop C, Plankey M: Queering medical education: Systematically assessing LGBTQI health competency and implementing reform. Med Educ Online 2018;23:1510703.

37. Martos A, Nezhad S, Meyer IH: Variations in sexual identity milestones among lesbians, gay men and bisexuals. Sex Res Social Policy 2015;12:24-33.

38. Institute of Medicine (US) Board on the Health of Select Populations. Collecting Sexual Orientation and Gender Identity Data in Electronic Health Records: Workshop Summary. Washington, DC: National Academies Press, 2013.

39. Maloney KM, Krakower DS, Ziobro D, et al.: Culturally competent sexual healthcare as a prerequisite for obtaining preexposure prophylaxis: Findings from a qualitative study. LGBT Health 2017;4:310-314.

40. Mosack KE, Brouwer AM, Petroll AE: Sexual identity, identity disclosure, and health care experiences: Is there evidence for differential homophobia in primary care practice? Womens Health Issues 2013;23:e341-e346.

41. Sexton MB, Davis MT, Anderson RE, et al.: Relation between sexual and gender minority status and suicide attempts among veterans seeking treatment for military sexual trauma. Psychol Serv 2018;15:357-362.

42. Mattocks KM, Sadler A, Yano EM, et al.: Sexual victimization, health status, and VA healthcare utilization among lesbian and bisexual OEF/OIF veterans. J Gen Intern Med 2013;28:S604-S608.

43. Grasso C, Goldhammer H, Funk D, et al.: Required sexual orientation and gender identity reporting by US health centers: First-year data. Am J Public Health 2019;109:1111-1118.

44. Bent-Goodley TB: The importance of advancing one social work: NASW 60 years later. Soc Work 2015;60:5-7.

45. Klein S: The Veterans Health Administration: Implementing Patient-Centered Medical Homes in the Nation's Largest Integrated Delivery System. New York, NY: The Commonwealth Fund, 2011.

46. Blosnich J, Foynes MM, Shipherd JC: Health disparities among sexual minority women veterans. J Womens Health (Larchmt) 2013;22:631-636.

47. VA Health Care: Better Data Needed to Assess the Health Outcomes of Lesbian, Gay, Bisexual, and Transgender Veterans. GAO-21-69. Washington, DC: U.S. Government Accountability Office, 2020.

Address correspondence to: Kristine E. Lynch, PhD VA Informatics and Computing Infrastructure VA Salt Lake City Health Care System 500 Foothill Drive Salt Lake City, UT 84148 USA

E-mail: kristine.lynch@hsc.utah.edu 